\title{
Comparison of Short- and Long-Duration Oxygen Treatment after Cerebral Asphyxia in Newborn Piglets
}

\author{
ANNE-BEATE SOLÅS, BERIT HOLTE MUNKEBY, AND OLA DIDRIK SAUGSTAD \\ Department of Pediatric Research [A.B.S., B.H.M., O.D.S.], Institute for Surgical Research [A.B.S., \\ B.H.M.], The National Hospital, University of Oslo, 0027 Oslo, Norway, and Institute for Experimental \\ Medical Research, Ullevaal University Hospital, 0027 Oslo, Norway [A.B.S., B.H.M.].
}

\begin{abstract}
We tested whether reoxygenation with $100 \% \mathrm{O}_{2}$ for $5 \mathrm{~min}$ after experimental asphyxia in newborn piglets was as efficient as $100 \% \mathrm{O}_{2}$ for 20 min compared with room air. Forty-one anesthetized piglets, 1-3 d old, were randomized to cerebral hypoxemia-ischemia-hypercapnia (HIH) or control $(n=5)$. HIH was achieved by ventilation with $8 \% \mathrm{O}_{2}$, temporary occlusion of the common carotid arteries, and adding of $\mathrm{CO}_{2}$. After $25 \mathrm{~min}$, reoxygenation-reperfusion was started with $100 \% \mathrm{O}_{2}$ for $20 \mathrm{~min}$ (group 1, $n=12$ ), $100 \% \mathrm{O}_{2}$ for $5 \min$ (group 2, $n=12$ ), or $21 \%$ $\mathrm{O}_{2}$ (group 3, $n=12$ ). All piglets were observed for $2 \mathrm{~h}$. During reoxygenation-reperfusion, significantly higher blood pressure and more complete restoration of microcirculation (laser Doppler flow) in the cerebral cortex was found in both groups reoxygenated with $100 \% \mathrm{O}_{2}$ compared with $21 \% \mathrm{O}_{2}$ (regional cerebral blood flow $\geq 100 \%$ versus $70 \%$ of baseline, $p=0.04$ ). Reoxygenation with $100 \% \mathrm{O}_{2}$ for $5 \mathrm{~min}$ was as efficient as $20 \mathrm{~min}$. Oxygen delivery in cortex was significantly higher in groups 1 and 2 compared with group $3(p=0.03)$, but there were no significant differences in cerebral metabolic rate for oxygen. In the striatum, no significant differences in flow or extracellular
\end{abstract}

\section{ABSTRACT}

glutamate, glycerol, and lactate/pyruvate ratio were found between the groups. In conclusion, after experimental asphyxia, newborn piglets can be reoxygenated as efficiently with $100 \% \mathrm{O}_{2}$ for only $5 \mathrm{~min}$ as $100 \% \mathrm{O}_{2}$ for 20 min compared with room air.

(Pediatr Res 56: 125-131, 2004)

BE, base excess
$\mathrm{CaO}_{2}$, arterial $\mathrm{O}_{2}$ content
$\mathrm{CvSSO}_{2}$, sagittal sinus $\mathrm{O}_{2}$ content
$\mathbf{C B F}$, cerebral blood flow
$\mathrm{CMRO}_{2}$, metabolic rate for oxygen
DO $_{2}$, oxygen delivery
HIH, hypoxemia-ischemia-hypercapnia
MABP, mean arterial blood pressure
$\mathrm{OER}_{\text {, oxygen extraction ratio }}$
Paco $_{2}$, arterial $\mathrm{CO}_{2}$ tension
Pao $_{2}$, arterial $\mathrm{O}_{2}$ tension
ROS, reactive oxygen species

The optimum way to reoxygenate asphyxiated newborns is still not known. Infants in need of resuscitation are often exposed to high concentrations of $\mathrm{O}_{2}$. The possibility of increasing the load of toxic ROS by giving additional $\mathrm{O}_{2}$ during resuscitation is, however, still of major concern (1). Several experimental and clinical studies from our group (2-7) have shown that asphyxiated newborns may be reoxygenated as efficiently with $21 \% \mathrm{O}_{2}$ as with $100 \% \mathrm{O}_{2}$. However, in two recent animal studies using a model of combined cerebral hypoxemia-ischemia in newborn piglets, we found signifi-

Received March 11, 2003; accepted November 21, 2003.

Correspondence: Anne-Beate Solås, M.D., Department of Anaesthesiology, The National Hospital, NO -0027 Oslo, Norway; e-mail: absolaas@klinmed.uio.no

Supported in part by grants from the Medical Faculty, University of Oslo; the Norwegian Society of Anaesthesiology; and Rolf Geir Gjertsen's Foundation. A.B.S. is a research fellow with the Norwegian Council on Cardiovascular Diseases.

DOI: 10.1203/01.PDR.0000128978.90201.1D cantly higher MABP and better restoration of microcirculation in cerebral cortex after initial reoxygenation for the first $30 \mathrm{~min}$ with $100 \% \mathrm{O}_{2}$ compared with $21 \% \mathrm{O}_{2}$. In the first study (8), in which piglets were exposed to $20 \mathrm{~min}$ of combined hypoxemiaischemia alone, we also found significantly higher levels of excitatory amino acids in the striatum after reoxygenation with $21 \% \mathrm{O}_{2}$. In the second study (in press), a moderate hypercapnia was added to the hypoxic-ischemic insult to more closely simulate perinatal asphyxia. This seemed to result in a less severe insult, as no significant differences in biochemical markers were found between the groups, whereas differences in MABP and microcirculation in cerebral cortex still persisted.

Exposure to $\mathrm{O}_{2}$ during resuscitation can be limited in two ways, either by reducing the concentration or by limiting the time of exposure. The purpose of the present study was to test whether initial reoxygenation after combined $\mathrm{HIH}$ in newborn piglets with $100 \% \mathrm{O}_{2}$ for only $5 \mathrm{~min}$ was as efficient as $20 \mathrm{~min}$ 
compared with reoxygenation with $21 \% \mathrm{O}_{2}$. Outcome measures were MABP, changes in microcirculation in cerebral cortex and striatum (laser Doppler flow), and biochemical markers (glutamate, glycerol, and lactate/pyruvate ratio) in the striatum (in vivo microdialysis). To monitor oxygen metabolism we calculated cerebral OER and relative changes in $\mathrm{DO}_{2}$ and $\mathrm{CMRO}_{2}$ in the cortex.

\section{METHODS}

Animal preparation. Forty-nine piglets (1-3 d old, 1.1-2.5 $\mathrm{kg}$ ) were delivered from a local farmer on the day of the experiments. Eight piglets were excluded because of low $\mathrm{Hb}$ at baseline ( $<5 \mathrm{~g} / \mathrm{dL}, n=4)$, low basal $\mathrm{PaO}_{2}(<9.0 \mathrm{kPa}, n=2)$, and death during the asphyxic insult $(n=2)$.

Anesthesia was induced by halothane, an ear vein was cannulated, halothane was discontinued, and the piglets were given pentobarbital sodium $20 \mathrm{mg} / \mathrm{kg}$ and fentanyl $50 \mu \mathrm{g} / \mathrm{kg}$ i.v. as a bolus injection. Anesthesia was maintained with a continuous fentanyl infusion $(25-50 \mu \mathrm{g} / \mathrm{kg} / \mathrm{h})$ and a continuous midazolam infusion $(0.25 \mathrm{mg} / \mathrm{kg} / \mathrm{h})$. Midazolam was temporarily discontinued during HIH. Pancuronium was given every hour $(0.1 \mathrm{mg} / \mathrm{kg}$ i.v.). A continuous i.v. infusion containing $0.7 \% \mathrm{NaCl}$ and $1.25 \%$ glucose was given at a rate of 10 $\mathrm{mL} / \mathrm{kg} / \mathrm{h}$. Blood glucose levels were maintain between 4 and $10 \mathrm{mM}$.

A tracheotomy was performed, and a pressure-controlled ventilator (Dräger Babylog 8000 Plus, Drägerwerk AG, Lübeck, Germany) ventilated the piglets at a rate of 30 breaths/ min. Normoventilation $\left(\mathrm{PaCO}_{2} 4.5-6.0 \mathrm{kPa}\right)$ was maintained during the stabilizing and reoxygenation-reperfusion period by adjusting the tidal volume with a constant inspiratory time of $0.5 \mathrm{~s}$ and a positive end-expiratory pressure of $3 \mathrm{~cm} \mathrm{H}_{2} \mathrm{O}$. Before $\mathrm{HIH}$ was induced, all piglets were ventilated with $21 \%$ oxygen. Inspired fraction of $\mathrm{O}_{2}$ and end tidal $\mathrm{CO}_{2}$ were continuously monitored (Datex Normocap Oxy, Datex, Helsinki, Finland). Rectal temperature was kept between 38 and $39.5^{\circ} \mathrm{C}$ with a heating blanket.

Both femoral arteries were cannulated for continuous measurements of MABP and blood sampling. The common carotid arteries on both sides were exposed through a small incision in the neck at the level of the fourth cervical vertebra.

The piglets were placed with the head fixed in a stereotaxic frame (David Kopf Instruments, Tujunga, CA, U.S.A.). The scalp was removed and three holes, one $3 \mathrm{~mm}$ in diameter and two $3 \times 6 \mathrm{~mm}$, were drilled through the skull. Small dural incisions were made and one microdialysis probe was implanted into the striatum ( $8 \mathrm{~mm}$ anterior, $4.5 \mathrm{~mm}$ lateral, and 19 $\mathrm{mm}$ vertical to the bregma) on the right side. Opposite the microdialysis probe, a laser Doppler probe was implanted into the striatum on the left side. A second laser Doppler probe was implanted into the frontal cerebral cortex on the right side (16 $\mathrm{mm}$ anterior, $5 \mathrm{~mm}$ lateral to the bregma, and $5 \mathrm{~mm}$ vertical from the surface of the cortex). The coordinates for the cerebral striatum and cortex have been verified through neuropathological postmortem examination in earlier studies (9). A 3-mm diameter hole was drilled in the midline of the skull about 5 $\mathrm{mm}$ posterior of the bregma, and a cannula (Venflon, outside diameter $0.8 \mathrm{~mm}$ ) was inserted through the intact dura into the superior sagittal sinus.

At the end of the experiment, the piglets were killed with a bolus injection of pentobarbital sodium, and brains were sliced to confirm the position of the probes.

Experimental protocol. After a 60-min recovery period from surgery, the piglets were randomized to four groups. Group 1 was subjected to 25 min of combined $\mathrm{HIH}$ followed by reperfusion and reoxygenation with $100 \% \mathrm{O}_{2}$ for the first 20 min and then $21 \% \mathrm{O}_{2}$ for another $100 \mathrm{~min}(n=12)$. Group 2 was subjected to 25 min of combined HIH followed by reperfusion and reoxygenation with $100 \% \mathrm{O}_{2}$ for the first $5 \mathrm{~min}$ and then $21 \% \mathrm{O}_{2}$ for $115 \mathrm{~min}(n=12)$. Group 3 was subjected to combined HIH for 25 min followed by reperfusion and reoxygenation with $21 \% \mathrm{O}_{2}$ for $120 \mathrm{~min}(n=12)$. Group 4 (control) received no $\mathrm{HIH}$ and was normoventilated with $21 \% \mathrm{O}_{2}$ for a total of $145 \min (n=5)$. Hypoxemia was induced by ventilation with $8 \% \mathrm{O}_{2}$ in $\mathrm{N}_{2}$, hypercapnia by adding $\mathrm{CO}_{2}$ to the inspiratory gas $\left(\mathrm{PaCO}_{2}\right.$ aimed at $\left.8.0-9.0 \mathrm{kPa}\right)$, and ischemia by temporary occlusion of the common carotid arteries on both sides with small, nontraumatizing metallic clamps. At the start of reoxygenation-reperfusion, clamps were released and the $\mathrm{CO}_{2}$ was discontinued.

Blood samples. Blood samples from the femoral artery and sagittal sinus were taken before HIH (baseline), just before start of reoxygenation-reperfusion and then after 5, 10, 20, 30, $45,60,90$, and $120 \mathrm{~min}$ of reoxygenation-reperfusion. Temperature-corrected blood gases and acid/base status were measured with a blood gas analyzer AVL Omni 1-9 (AVL LIST $\mathrm{GmbH}$, Graz, Austria). $\mathrm{Hb}$ and arterial and venous oxygen saturation were measured with an OSM 3 Hemoximeter (Radiometer, Copenhagen, Denmark). A 3-fold volume of normal saline replaced the withdrawn blood.

Microdialysis. Microdialysis probes (CMA 10, CMA, Stockholm, Sweden) with a membrane length of $4 \mathrm{~mm}$ and a molecular mass cutoff of 20,000 D were perfused at $3 \mu \mathrm{L} / \mathrm{min}$ with an unbuffered electrolyte solution as previously described (5). Samples for measurements of glutamate, lactate, pyruvate, and glycerol were collected at 10-min intervals and analyzed using CMA 600 Microdialysis Analyzer (CMA), based on enzyme reagents and colorimetric analysis. Glutamate and glycerol measurements are presented as the concentrations measured in the microdialysis fluid. This concentration is always lower than the actual concentration in the extracellular fluid, and is dependent on perfusion flow rate, surface area of the probe, and molecular cutoff. Due to contamination of the vials, microdialysis results were excluded in two animals (one in group 1 and one in group 2).

Laser Doppler flowmetry. Measurements of changes in cerebral microcirculation in cortex and striatum were performed with 2 LDF 100A Laser Doppler Flow Modules (BIOPAC Systems, Inc., Santa Barbara, CA, U.S.A.). The flowmeter emits a temperature-stabilized semiconductor laser light with a wavelength of $780 \pm 10 \mathrm{~nm}$, which is directed to the tissue by an optical fiber through a micro-needle probe (TSD 145, length $25 \mathrm{~mm}$, diameter $480 \mu \mathrm{m}$ ). The magnitude and frequency distribution of the Doppler-shifted light is proportional to the number and velocity of red blood cells (i.e. blood perfusion) 
that are moving through the illuminated area of the tissue with a measurement depth of about $1 \mathrm{~mm}$. The Doppler shift is independent of movement direction. Blood flow is computed by determining the product of blood volume and velocity and gives only a relative, not an absolute, value that is expressed in arbitrary units (10). Backscatter signal (tissue remittance) for each probe was recorded throughout the experiment to ensure adequacy and stability of the reading. The signal was considered inadequate if backscatter signal was $<5 \%$. Micro-needle probes were new and precalibrated by the manufacturer. In all animals a (close to) zero reading was obtained immediately after death.

Calculations. Arterial $\left(\mathrm{CaO}_{2}\right)$ and venous sagittal sinus $\left(\mathrm{CvssO}_{2}\right) \mathrm{O}_{2}$ content were calculated as $\mathrm{CaO}_{2}=(1.39 \times \mathrm{Hb} \times$ arterial saturation $)+\left(\mathrm{PaO}_{2} \times 0.003\right)$, and $\mathrm{CvssO}_{2}=(1.39 \times$ $\mathrm{Hb} \times$ venous sagittal sinus saturation $)+\left(\mathrm{Pvss}_{2} \times 0.003\right)$.

Relative changes in $\mathrm{DO}_{2}$ were calculated as $\mathrm{DO}_{2}=\mathrm{CBF}(\%$ of baseline) $\times \mathrm{CaO}_{2}$.

OER was calculated as OER $=\left(\mathrm{CaO}_{2}-\mathrm{CvSSO}_{2}\right) / \mathrm{CaO}_{2}$ (or $\mathrm{CMRO}_{2} / \mathrm{DO}_{2}$ ).

Relative changes in $\mathrm{CMRO}_{2}$ was calculated as $\mathrm{CMRO}_{2}=$ $\mathrm{CBF}$ (percentage of baseline) $\times\left(\mathrm{CaO}_{2}-\mathrm{CvssO}_{2}\right)$.

Due to problems in aspirating blood from the sagittal sinus at the end of the insult/start of reoxygenation-reperfusion, calculations of oxygen metabolism had to be excluded in six animals (two in each HIH group).

Statistics. Values are presented as mean \pm SD. The three $\mathrm{HIH}$ groups were compared at baseline and at end of $\mathrm{HIH}$ to investigate whether there were any differences between the groups before the start of reoxygenation-reperfusion by using a one-way ANOVA followed by a Games/Howell post hoc test. When comparing two time points in the same group, a paired $t$ test with or without Welch's correction (for unequal variance) was used. A repeated measures ANOVA followed by a Games/ Howell post hoc test was used to compare values for the groups during the reoxygenation-reperfusion period. The control group was used to assess the stability of the model, and was not directly compared with the HIH groups. Two-sided $p$ values $<$ 0.05 were considered significant. All analyses were done with the statistical computer program StatView 5.0 (Abacus Concepts, Berkeley, CA, U.S.A.).
Approval. The study was approved by the Norwegian Animal Experimental Board.

\section{RESULTS}

There were no significant differences between the three $\mathrm{HIH}$ groups in any measured variable at baseline or at the start of reoxygenation-reperfusion.

Blood gases and blood pressure. Except for a significantly higher $\mathrm{PaO}_{2}(p<0.001)$ in groups 1 and 2 compared with group 3 during the period the two groups received additional $\mathrm{O}_{2}$, there were no significant differences between the groups in $\mathrm{pH}, \mathrm{PaO}_{2}, \mathrm{PaCO}_{2}$, or BE (Table 1). At the start of reoxygenationreperfusion, $\mathrm{PacO}_{2}$ was $8.4 \pm 0.6 \mathrm{kPa}$, with no significant differences between the groups $(p=0.5)$.

During reoxygenation-reperfusion, there were significant differences in MABP (Fig. 1) between all groups $(p=0.005)$. MABP was highest in group 2 and lowest in group 3. At the end of the observation period, MABP was $77 \pm 10 \mathrm{~mm} \mathrm{Hg}$ in group 1, $85 \pm 13 \mathrm{~mm} \mathrm{Hg}$ in group 2, and $67 \pm 12 \mathrm{~mm} \mathrm{Hg}$ in group 3 , which was significantly lower than baseline in both group $1(p=0.003)$ and group $3(p=0.0002)$.

Laser Doppler flowmetry. Changes in microcirculation in the striatum and cortex are shown in Figure 2. Data are presented as percentage of baseline. Baseline values in arbitrary units were, in the striatum, $291 \pm 127$ in group $1,303 \pm$ 116 in group 2, and $279 \pm 156$ in group 3; and, in the cortex, $372 \pm 150$ in group $1,335 \pm 106$ in group 2 , and $392 \pm 144$ in group 3. In the striatum, blood flow decreased by $80 \%$ during HIH. During reoxygenation-reperfusion, flow was rapidly restored without any significant differences between the groups. There was, however, a considerable overshoot during the first $20 \mathrm{~min}$ of reoxygenation-reperfusion, especially in the two $\mathrm{O}_{2}$-treated groups, with flow values up to three times baseline in some animals. At the end of the observation period, blood flow was not significantly different from baseline in any group.

In the cortex, blood flow also decreased by $80 \%$ during $\mathrm{HIH}$. During reoxygenation-reperfusion, blood flow values returned to or exceeded baseline values within $5 \mathrm{~min}$ in the two groups receiving additional $\mathrm{O}_{2}$, whereas values in the room air group

Table 1. $\mathrm{pH}, \mathrm{PaO}_{2}, \mathrm{PCO}_{2}$, and $\mathrm{BE}$ (mean $\pm \mathrm{SD}$ )

\begin{tabular}{|c|c|c|c|c|c|c|c|}
\hline & & \multirow[b]{2}{*}{ Baseline } & \multirow[b]{2}{*}{ End $\mathrm{HIH}$} & \multicolumn{4}{|c|}{ Reoxygenation-reperfusion } \\
\hline & & & & $5 \mathrm{~min}$ & $20 \mathrm{~min}$ & $60 \mathrm{~min}$ & $120 \mathrm{~min}$ \\
\hline \multirow[t]{3}{*}{$\mathrm{pH}$} & Group 1 & $7.42 \pm 0.12$ & $7.02 \pm 0.15$ & $7.18 \pm 0.17$ & $7.21 \pm 0.16$ & $7.30 \pm 0.10$ & $7.34 \pm 0.09$ \\
\hline & Group 2 & $7.44 \pm 0.11$ & $7.08 \pm 0.11$ & $7.24 \pm 0.14$ & $7.25 \pm 0.12$ & $7.36 \pm 0.08$ & $7.40 \pm 0.04$ \\
\hline & Group 3 & $7.43 \pm 0.15$ & $7.05 \pm 0.11$ & $7.16 \pm 0.12$ & $7.23 \pm 0.09$ & $7.34 \pm 0.07$ & $7.39 \pm 0.05$ \\
\hline \multirow[t]{3}{*}{$\mathrm{PaO}_{2}(\mathrm{kPa})$} & Group 1 & $11.5 \pm 1.7$ & $4.4 \pm 0.9$ & $59.6 \pm 9.9^{*}$ & $54.6 \pm 13.9^{*}$ & $11.1 \pm 1.8$ & $10.9 \pm 1.5$ \\
\hline & Group 2 & $12.5 \pm 2.4$ & $4.0 \pm 0.8$ & $57.7 \pm 5.6^{*}$ & $12.9 \pm 2.2$ & $11.8 \pm 1.9$ & $11.7 \pm 1.7$ \\
\hline & Group 3 & $10.9 \pm 0.9$ & $4.6 \pm 0.9$ & $13.4 \pm 1.4$ & $12.0 \pm 1.5$ & $11.1 \pm 1.8$ & $10.7 \pm 1.3$ \\
\hline \multirow[t]{3}{*}{$\mathrm{PaCO}_{2}(\mathrm{kPa})$} & Group 1 & $5.1 \pm 0.4$ & $8.5 \pm 0.5$ & $4.9 \pm 0.5$ & $5.2 \pm 0.3$ & $5.3 \pm 0.3$ & $5.3 \pm 0.5$ \\
\hline & Group 2 & $5.1 \pm 0.3$ & $8.3 \pm 0.4$ & $4.9 \pm 0.3$ & $5.3 \pm 0.2$ & $5.3 \pm 0.9$ & $5.2 \pm 0.3$ \\
\hline & Group 3 & $5.2 \pm 0.3$ & $8.3 \pm 0.8$ & $5.0 \pm 0.4$ & $5.0 \pm 0.2$ & $5.2 \pm 0.3$ & $5.2 \pm 0.3$ \\
\hline \multirow[t]{3}{*}{$\mathrm{BE}(\mathrm{mmol} / \mathrm{L})$} & Group 1 & $0.2 \pm 3.9$ & $-14.4 \pm 7.5$ & $-14.8 \pm 7.4$ & $-12.3 \pm 7.1$ & $-6.9 \pm 6.1$ & $-4.3 \pm 5.4$ \\
\hline & Group 2 & $1.0 \pm 3.8$ & $-12.1 \pm 5.5$ & $-11.3 \pm 6.7$ & $-9.8 \pm 6.1$ & $-4.1 \pm 4.3$ & $-1.1 \pm 3.4$ \\
\hline & Group 3 & $0.7 \pm 3.2$ & $-13.8 \pm 5.0$ & $-14.5 \pm 5.3$ & $-12.1 \pm 4.2$ & $-5.1 \pm 4.2$ & $-1.9 \pm 3.6$ \\
\hline
\end{tabular}

$* p<0.0001$ group effect. 


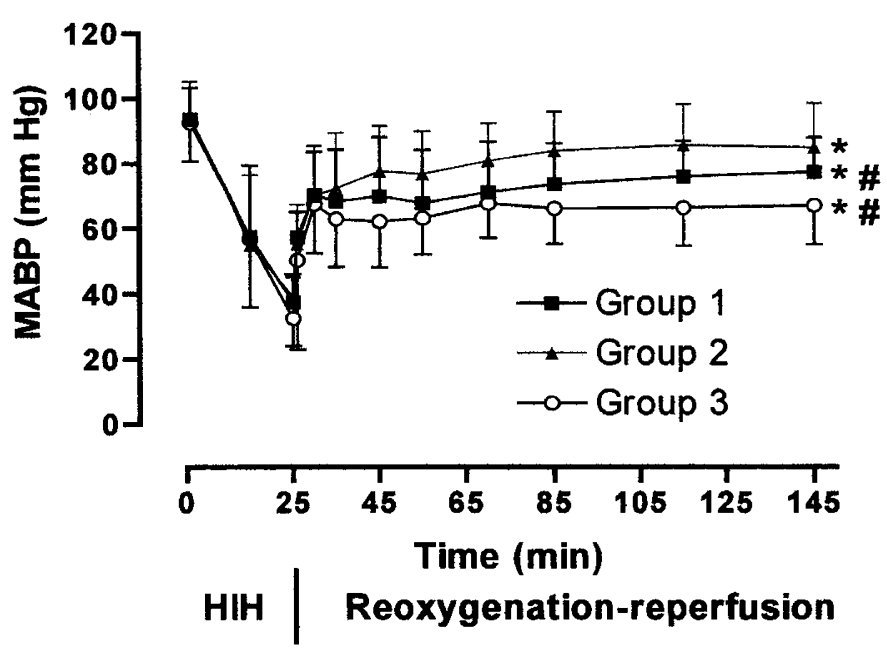

Figure 1. MABP during $\mathrm{HIH}$ and reoxygenation-reperfusion. Mean $\pm \mathrm{SD}$. Group 1 was reoxygenated with $100 \% \mathrm{O}_{2}$ for the initial 20 min, group 2 with $100 \% \mathrm{O}_{2}$ for the initial $5 \mathrm{~min}$, and group 3 was reoxygenated with $21 \% \mathrm{O}_{2} .{ }^{*} p$ $<0.05$ group difference. $\# p<0.05 v s$ baseline for the group.

reached approximately $70 \%$ of baseline. Repeated measures ANOVA for the whole reoxygenation-reperfusion period showed a significant group effect $(p=0.04)$, with significantly higher blood flow in groups 1 and 2 compared with the room air group. At the end of reoxygenation-reperfusion, blood flow was not significantly different from baseline in any group.

Oxygen metabolism. Cerebral OER and relative changes in cortical $\mathrm{DO}_{2}$ and $\mathrm{CMRO}_{2}$ are shown in Figure 3. $\mathrm{DO}_{2}$ in cortex was significantly higher $(p=0.03)$ during reoxygenationreperfusion in the two groups receiving additional $\mathrm{O}_{2}$ compared with the room air group. There was a near-significant difference in OER between the groups during reoxygenationreperfusion $(p=0.056)$, with the highest values in the room air group. There were no significant differences in changes in $\mathrm{CMRO}_{2}$ between the groups $(p=0.18)$ during reoxygenationreperfusion. At the end of the observation period, values were not significantly different from baseline.

Glutamate in striatum. Extracellular concentrations of glutamate in the striatum (Fig. 4) increased 4- to 5-fold during $\mathrm{HIH}$ and the first $10 \mathrm{~min}$ of reoxygenation-reperfusion. Values then started to decrease toward baseline values in all animals, but, in two animals in group 2 and three animals in group 3, a second increase occurred during the last $60 \mathrm{~min}$ of reoxygenation-reperfusion. The overall change from baseline to the end of reoxygenation-reperfusion was, however, not significantly different between the groups.

Glycerol and lactate/pyruvate ratio in striatum. Extracellular concentrations of glycerol in the striatum (Fig. 4) increased 2- to 3-fold during HIH and further during reoxygenationreperfusion without significant differences between the groups. At the end of the observation period, values were significantly higher than baseline for all groups $(p<0.05)$. Lactate/pyruvate ratio (Fig. 4) increased 12-16 times baseline values during $\mathrm{HIH}$, and started to decrease immediately during reoxygenation-reperfusion without any significant differences between the groups.
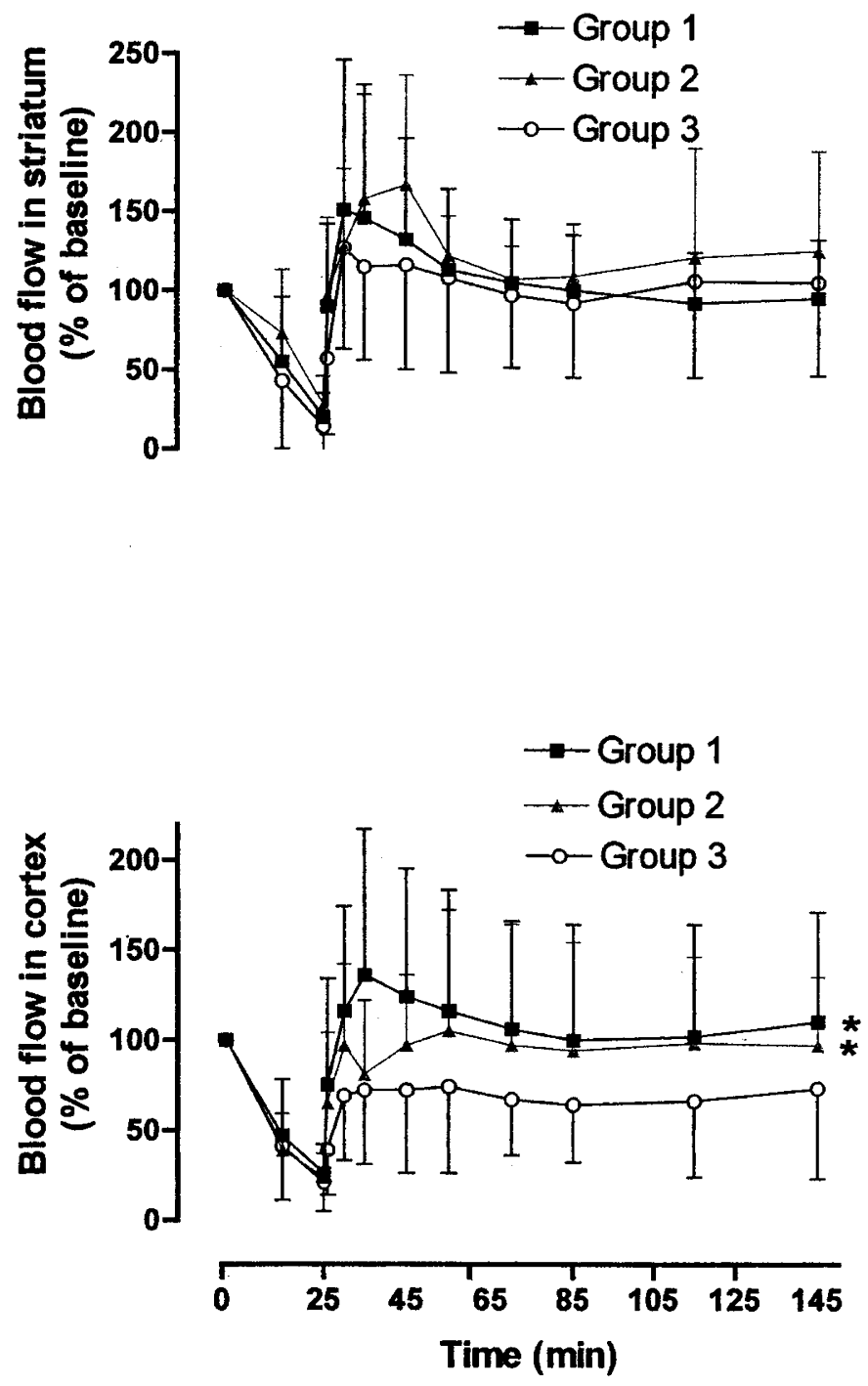

HIH Reoxygenation-reperfusion

Figure 2. Changes in microcirculation in the striatum and cortex during $\mathrm{HIH}$ and reoxygenation-reperfusion. Mean $\pm \mathrm{SD}$. Group 1 was reoxygenated with $100 \% \mathrm{O}_{2}$ for the initial $20 \mathrm{~min}$, group 2 with $100 \% \mathrm{O}_{2}$ for the initial $5 \mathrm{~min}$, and group 3 was reoxygenated with $21 \% \mathrm{O}_{2} .{ }^{*} p<0.05$ group effect.

Control group. All measured variables were stable throughout the observation period in the five control animals (data not shown).

\section{DISCUSSION}

In this study, we found significantly higher MABP and more complete restoration of microcirculation in the cerebral cortex in both groups reoxygenated with $100 \% \mathrm{O}_{2}$ compared with $21 \% \mathrm{O}_{2}$. Reoxygenation with $100 \% \mathrm{O}_{2}$ for 5 min was as efficient as $20 \mathrm{~min} . \mathrm{DO}_{2}$ in cortex was significantly higher in the two groups receiving additional oxygen compared with the room air group, and OER was near significantly higher in the room air group. In the striatum, however, no significant differences in flow or biochemical markers were found between the groups. 

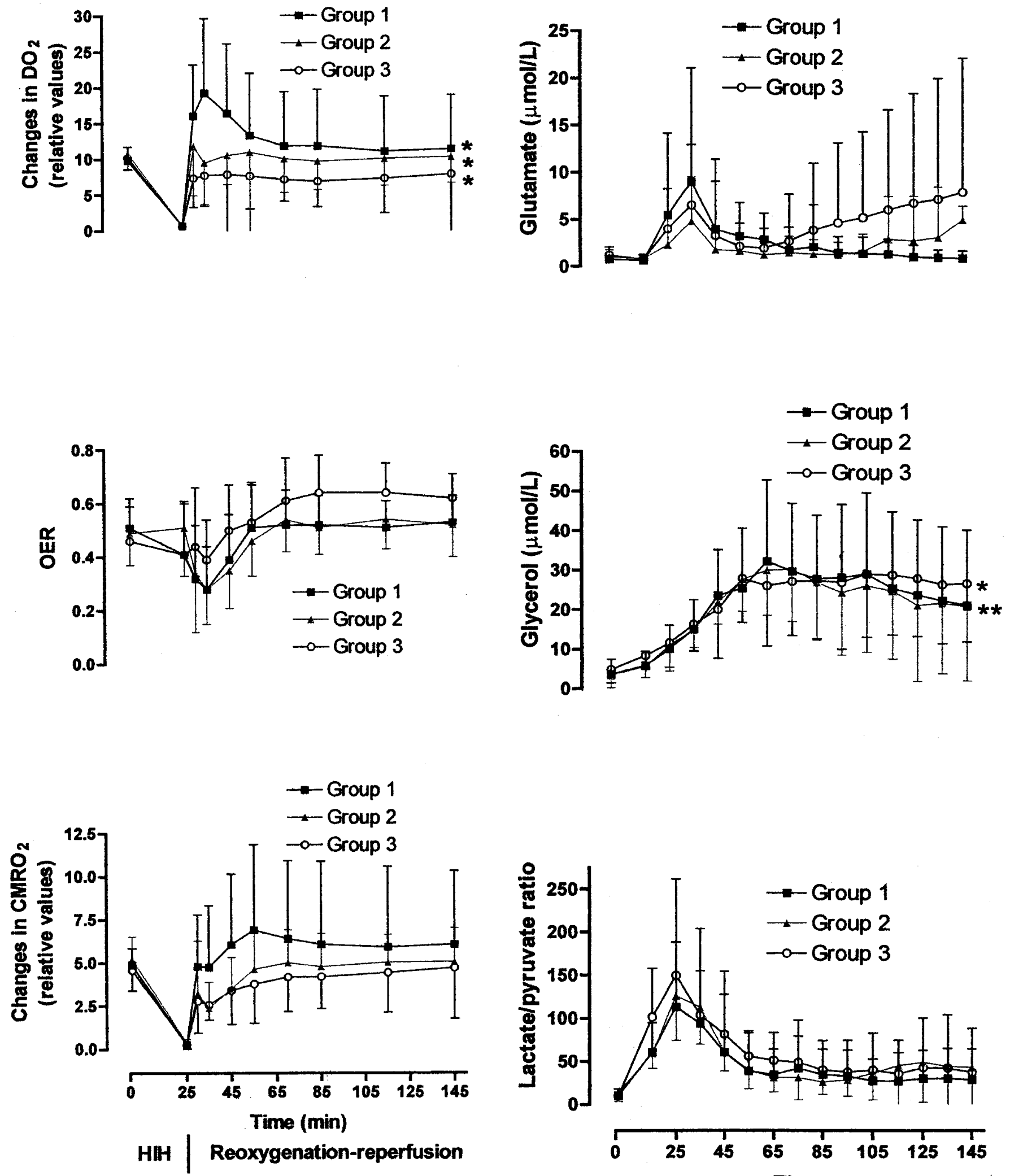

Figure 3. Relative changes in $\mathrm{DO}_{2}, \mathrm{OER}$, and $\mathrm{CMRO}_{2}$ in the cortex during $\mathrm{HIH}$ and reoxygenation-reperfusion. Mean $\pm \mathrm{SD}$. Group 1 was reoxygenated with $100 \% \mathrm{O}_{2}$ for the initial $20 \mathrm{~min}$, group 2 with $100 \% \mathrm{O}_{2}$ for the initial 5 min, and group 3 was reoxygenated with $21 \% \mathrm{O}_{2}$. Relative changes in $\mathrm{DO}_{2}$ was calculated as $\mathrm{DO}_{2}=\mathrm{CBF}(\%$ of baseline $) \times \mathrm{CaO}_{2}$. OER was calculated as OER $=\left(\mathrm{CaO}_{2}-\mathrm{CvssO}_{2}\right) / \mathrm{CaO}_{2}\left(\right.$ or $\left.\mathrm{CMRO}_{2} / \mathrm{DO}_{2}\right)$. Relative change in $\mathrm{CMRO}_{2}$ was calculated as $\mathrm{CMRO}_{2}=\mathrm{CBF}$ (percentage of baseline) $\times\left(\mathrm{CaO}_{2}\right.$ $\left.-\mathrm{CvsSO}_{2}\right) .{ }^{*} p<0.05$ group effect.

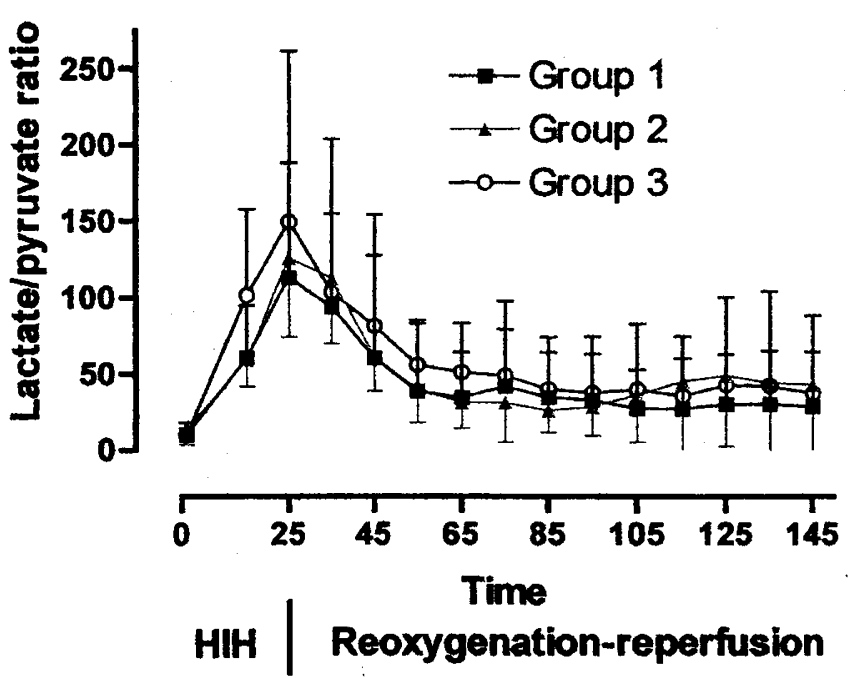

Figure 4. Extracellular concentrations of glutamate, glycerol, and lactate/ pyruvate ratio in the striatum during $\mathrm{HIH}$ and reoxygenation-reperfusion. Mean \pm SD. Group 1 was reoxygenated with $100 \% \mathrm{O}_{2}$ for the initial $20 \mathrm{~min}$, group 2 with $100 \% \mathrm{O}_{2}$ for the initial $5 \mathrm{~min}$, and group 3 was reoxygenated with $21 \% \mathrm{O}_{2} .{ }^{*} p<0.05 v s$ baseline for the group. 
The findings of higher flow in the cortex after reoxygenation with $100 \%$ compared with $21 \% \mathrm{O}_{2}$, are in accordance with findings in two of our previous animal studies using comparable models $(8$, in press). In the two groups receiving additional $\mathrm{O}_{2}$, microcirculation in cortex rapidly returned to or exceeded baseline values during reoxygenation-reperfusion, whereas values in the room air group reached approximately $70 \%$ of baseline. Threshold values for regional $\mathrm{CBF}$ after asphyxia have not been established. The findings of significantly higher $\mathrm{DO}_{2}$ in the two groups receiving $100 \% \mathrm{O}_{2}$ and the nearly significantly higher OER in the $21 \% \mathrm{O}_{2}$ group may indicate a borderline, but perhaps sufficient, cortical perfusion after reoxygenation with $21 \% \mathrm{O}_{2}$ compared with $100 \% \mathrm{O}_{2}$ in this model. Maintaining normal $\mathrm{CMRO}_{2}$ is necessary for normal brain function. The brain can maintain a stable $\mathrm{CMRO}_{2}$ either by increasing $\mathrm{CBF}$ or by increasing $\mathrm{O}_{2}$ extraction. If $\mathrm{CBF}$ is inadequate, OER will increase until this compensatory mechanism is exhausted and $\mathrm{CMRO}_{2}$ finally falls. In this study, changes in $\mathrm{CMRO}_{2}$ were not significantly different between the groups, and values at the end of the observation period were not significantly different from baseline in any group, findings that perhaps indicate that even reoxygenation with room air only is safe in this model. OER is normally around 0.45 both in newborn piglets (11), human adults (12), and neonates (13), and values exceeding 0.75 are conventionally accepted as indicating tissue ischemia (14). However, results from studies in a middle cerebral artery occlusion-reperfusion primate model (15) indicate that $\mathrm{CMRO}_{2}$ is a better predictor of reversible or irreversible brain damage than $\mathrm{CBF}$ and OER. In the present study, only relative changes in CBF were measured, and care must be taken when $\mathrm{CBF}$ results and calculated variables are interpreted.

The finding of perhaps greatest interest in the present study was that reoxygenation with $100 \% \mathrm{O}_{2}$ for only 5 min was as efficient as $20 \mathrm{~min}$ for all variables measured. Somehow, a brief exposure to oxygen for $5 \mathrm{~min}$ seems to trigger the same mechanisms that restore blood pressure, microcirculation, and oxygen metabolism in cortex more completely than in piglets reoxygenated with $100 \% \mathrm{O}_{2}$ for 20 or 30 min (8) compared with room air. Under normal conditions, hyperoxia induces cerebral vasoconstriction (16), but this oxygen reactivity may be lost when tissue is at risk of ischemia (17). It is known that free oxygen radicals are potent vasoregulators and can have a dilating effect on both cerebral arterioles and arteries $(18,19)$. Endothelial cells play a key role in the regulation of vascular tone, and a very fine balance exists between relaxing and contracting factors during asphyxia and reoxygenationreperfusion (i.e. production and action of ROS, nitric oxide, and peroxynitrite). We did not measure any of these substances in the present study, but high oxygen tension contributes substantially to the accumulation of ROS, and significantly higher cerebral NO concentrations have been demonstrated during reoxygenation with $100 \%$ compared with $21 \% \mathrm{O}_{2}$ after hypoxia in piglets (20).

The cerebral cortex, basal ganglia, and brainstem are areas at special risk during hypoxic-ischemic insults in both term babies and piglets (21-23). Animal studies have shown that the mature fetus reacts to an asphyxic insult by increasing and redistributing $\mathrm{CBF}$, especially to the brainstem and central parts of the brain (24-26), but as the insult persists, a reduction in CBF occurs (25). After the insult, a transient hyperperfusion may be seen (27). We have not measured changes in microcirculation in the striatum in this model before, but our findings are in accordance with previous results reported from a different study where no differences in flow in the striatum were found after reoxygenation with $100 \%$ compared with $21 \% \mathrm{O}_{2}$ in newborn piglets (28). Regional differences in mechanisms for regulation of $\mathrm{CBF}$ could possibly explain differences in response to $100 \% \mathrm{O}_{2}$ and room air during reoxygenationreperfusion in different parts of the brain. It has been suggested that the relative vasoconstriction in cerebral cortex during and after acute asphyxia may be sympathetically mediated, whereas vasodilatation in central parts of the brain may be consistent with chemical control $(26,29)$.

A transient hyperperfusion was seen both in the cortex and striatum, especially in the two oxygen-treated groups. This reactive hyperemia after asphyxia has been of some concern, as it in some studies has been associated with a fall in $\mathrm{CMRO}_{2}$ despite a marked increase in $\mathrm{DO}_{2}(30)$. This was not the case in the present study, and recent positron emission tomography studies in both humans and animals have indicated that early hyperperfusion following ischemia is not necessarily detrimental per se (31).

Extracellular concentrations of glycerol, lactate/pyruvate ratio, and glutamate are well-known markers of cell membrane damage, ischemia, and energy failure in the brain (32). No significant differences between the groups were found during reoxygenation-reperfusion. This could reflect the finding of generally good restoration of flow in the striatum in all groups. In this model, room air resuscitation therefore seems to give an adequate reoxygenation at least in the striatum. In the present study, biochemical markers were, however, not measured in the cortex. This would have been of great interest, inasmuch as significant differences in flow and $\mathrm{DO}_{2}$ but not $\mathrm{CMRO}_{2}$ were found between the two oxygen-treated and the room air group.

The repeated findings of significantly higher MABP after reoxygenation with $100 \%$ compared with $21 \% \mathrm{O}_{2}$ in this model have been somewhat unexpected. No such differences have been demonstrated in the numerous previous studies from our group using the model of global hypoxemia without clamping of cerebral vessels. However, hyperoxia has been shown to cause increased systemic vascular resistance in both dogs (33) and humans (34). Our study was not designed to look specifically at cardiovascular function during asphyxia and reoxygenation-reperfusion. Further studies addressing this issue are therefore needed.

In conclusion, significantly higher MABP and more complete restoration of microcirculation and $\mathrm{DO}_{2}$ in the cerebral cortex were found in both groups reoxygenated with $100 \% \mathrm{O}_{2}$ compared with $21 \% \mathrm{O}_{2}$ after experimental asphyxia in newborn piglets. There were no significant differences in $\mathrm{CMRO}_{2}$ between the groups. In the striatum, no significant differences in flow or biochemical markers were found. Reoxygenation with $100 \% \mathrm{O}_{2}$ for 5 min was as efficient as $20 \mathrm{~min}$, a finding that indicates that exposure to additional $\mathrm{O}_{2}$ during resuscitation at least can be limited in time in this model. 
Acknowledgments. The authors thank the staff at the Institute for Experimental Medical Research, Ullevaal University Hospital, for their skilled technical assistance, enthusiasm, and support.

\section{REFERENCES}

1. Vento M, Asensi M, Sastre J, Garcia-Sala F, Pallardo FV, Vina J 2001 Resuscitation with room air instead of $100 \%$ oxygen prevents oxidative stress in moderately asphyxiated term neonates. Pediatrics 107:642-647

2. Rootwelt T, Loberg EM, Moen A, Oyasaeter S, Saugstad OD 1992 Hypoxemia and reoxygenation with $21 \%$ or $100 \%$ oxygen in newborn pigs: changes in blood pressure, base deficit, and hypoxanthine and brain morphology. Pediatr Res 32:107-113

3. Rootwelt T, Odden JP, Hall C, Ganes T, Saugstad OD 1993 Cerebral blood flow and evoked potentials during reoxygenation with 21 or $100 \% \mathrm{O}_{2}$ in newborn pigs. J Appl Physiol 75:2054-2060

4. Feet BA, Gilland E, Groenendaal F, Brun NC, Hellstrom-Westas L, Hagberg H, Saugstad OD 1998 Cerebral excitatory amino acids and $\mathrm{Na}^{+}, \mathrm{K}^{+}$-ATPase activity during resuscitation of severely hypoxic newborn piglets. Acta Paediatr 87:889-895

5. Feet BA, Yu XQ, Rootwelt T, Oyasaeter S, Saugstad OD 1997 Effects of hypoxemia and reoxygenation with $21 \%$ or $100 \%$ oxygen in newborn piglets: extracellula hypoxanthine in cerebral cortex and femoral muscle. Crit Care Med 25:1384-1391

6. Ramji S, Ahuja S, Thirupuram S, Rootwelt T, Rooth G, Saugstad OD 1993 Resuscitation of asphyxic newborn infants with room air or $100 \%$ oxygen. Pediatr Res 34:809-812

7. Saugstad OD, Rootwelt T, Aalen O 1998 Resuscitation of asphyxiated newborn infants with room air or oxygen: an international controlled trial: the Resair 2 study. Pediatrics 102:e1

8. Solas AB, Kutzsche S, Vinje M, Saugstad OD 2001 Cerebral hypoxemia-ischemia and reoxygenation with $21 \%$ or $100 \%$ oxygen in newborn piglets: effects on extracellular levels of excitatory amino acids and microcirculation. Pediatr Crit Care Med $2: 340-345$

9. Feet BA, Brun NC, Hellstrom-Westas L, Svenningsen NW, Greisen G, Saugstad OD 1998 Early cerebral metabolic and electrophysiological recovery during controlled hypoxemic resuscitation in piglets. J Appl Physiol 84:1208-1216

10. Nilsson GE, Tenland T, Oberg PA 1980 Evaluation of a laser Doppler flowmeter for measurement of tissue blood flow. IEEE Trans Biomed Eng 27:597-604

11. Brown DW, Hadway J, Lee TY 2003 Near-infrared spectroscopy measurement of oxygen extraction fraction and cerebral metabolic rate of oxygen in newborn piglets. Pediatr Res 54:861-867

12. Leenders KL, Perani D, Lammertsma AA, Heather JD, Buckingham P, Healy MJ, Gibbs JM, Wise RJ, Hatazawa J, Herold S, et al. 1990 Cerebral blood flow, blood volume and oxygen utilization. Normal values and effect of age. Brain 113:27-47

13. Takahashi T, Shirane R, Sato S, Yoshimoto T 1999 Developmental changes of cerebral blood flow and oxygen metabolism in children. AJNR Am J Neuroradio 20:917-922

14. Hutchinson PJ, Gupta AK, Fryer TF, Al-Rawi PG, Chatfield DA, Coles JP, O'Connell MT, Kett-White R, Minhas PS, Aigbirhio FI, Clark JC, Kirkpatrick PJ, Menon DK, Pickard JD 2002 Correlation between cerebral blood flow, substrate delivery, and metabolism in head injury: a combined microdialysis and triple oxygen positron emission tomography study. J Cereb Blood Flow Metab 22:735-745
15. Frykholm P, Andersson JL, Valtysson J, Silander HC, Hillered L, Persson L, Olsson Y, Yu WR, Westerberg G, Watanabe Y, Langstrom B, Enblad P 2000 A metabolic threshold of irreversible ischemia demonstrated by PET in a middle cerebral artery occlusion-reperfusion primate model. Acta Neurol Scand 102:18-26

16. Niijima S, Shortland DB, Levene MI, Evans DH 1988 Transient hyperoxia and cerebral blood flow velocity in infants born prematurely and at full term. Arch Dis Child 63:1126-1130

17. Menzel M, Doppenberg EM, Zauner A, Soukup J, Reinert MM, Clausen T, Brockenbrough PB, Bullock R 1999 Cerebral oxygenation in patients after severe head injury: monitoring and effects of arterial hyperoxia on cerebral blood flow, metabolism and intracranial pressure. J Neurosurg Anesthesiol 11:240-251

18. Wei EP, Christman CW, Kontos HA, Povlishock JT 1985 Effects of oxygen radicals on cerebral arterioles. Am J Physiol 248:H157-H162

19. Iida Y, Katusic ZS 2000 Mechanisms of cerebral arterial relaxations to hydrogen peroxide. Stroke 31:2224-2230

20. Kutzsche S, Kirkeby OJ, Rise IR, Saugstad OD 1999 Effects of hypoxia and reoxygenation with $21 \%$ and $100 \%$-oxygen on cerebral nitric oxide concentration and microcirculation in newborn piglets. Biol Neonate 76:153-167

21. Low JA, Robertson DM, Simpson LL 1989 Temporal relationships of neuropathologic conditions caused by perinatal asphyxia. Am J Obstet Gynecol 160:608-614

22. Rorke LB 1992 Perinatal brain damage. In: Adams JH, Duchen LW (eds) Greenfield's Neuropathology. Oxford University Press, New York, pp 639-708

23. Martin LJ, Brambrink A, Koehler RC, Traystman RJ 1997 Primary sensory and forebrain motor systems in the newborn brain are preferentially damaged by hypoxiaischemia. J Comp Neurol 377:262-285

24. Ashwal S, Dale PS, Longo LD 1984 Regional cerebral blood flow: studies in the fetal lamb during hypoxia, hypercapnia, acidosis, and hypotension. Pediatr Res 18:13091316

25. Lou HC, Tweed WA, Davies JM 1985 Preferential blood flow increase to the brain stem in moderate neonatal hypoxia: reversal by naloxone. Eur J Pediatr 144:225-227

26. Goplerud JM, Wagerle LC, Delivoria-Papadopoulos M 1989 Regional cerebral blood flow response during and after acute asphyxia in newborn piglets. J Appl Physiol 66:2827-2832

27. Berger R, Lehmann T, Karcher J, Schachenmayr W, Jensen A 1996 Relation between cerebral oxygen delivery and neuronal cell damage in fetal sheep near term. Reprod Fertil Dev 8:317-321

28. Huang CC, Yonetani M, Lajevardi N, Delivoria-Papadopoulos M, Wilson DF, Pastuszko A 1995 Comparison of postasphyxial resuscitation with $100 \%$ and $21 \%$ oxygen on cortical oxygen pressure and striatal dopamine metabolism in newborn piglets. J Neurochem 64:292-298

29. Goplerud JM, Wagerle LC, Delivoria-Papadopoulos M 1991 Sympathetic nerve modulation of regional cerebral blood flow during asphyxia in newborn piglets. Am J Physiol 260:H1575-H1580

30. Rosenberg AA 1986 Cerebral blood flow and $\mathrm{O}_{2}$ metabolism after asphyxia in neonatal lambs. Pediatr Res 20:778-782

31. Marchal G, Young, AR, Baron JC 1999 Early postischemic hyperperfusion: pathophysiologic insights from positron emission tomography. J Cereb Blood Flow Metab 19:467-482

32. Hillered, L, Persson, L. 1999 Neurochemical monitoring of the acutely injured human brain. Scand J Clin Lab Invest Suppl 229:9-18

33. Lodato RF 1989 Decreased $\mathrm{O}_{2}$ consumption and cardiac output during normobaric hyperoxia in conscious dogs. J Appl Physiol 67:1551-1559

34. Reinhart K, Bloos F, Konig F, Bredle D, Hannemann L 1991 Reversible decrease of oxygen consumption by hyperoxia. Chest 99:690-694 